\title{
Lung Stem and Progenitor Cells
}

\author{
Karthikeyan Ardhanareeswaran Maria Mirotsou \\ Duke Cardiovascular Research Center and Mandel Center for Hypertension and Atherosclerosis Research, \\ Duke University Medical Center, Durham, N.C., USA
}

\section{Key Words}

Lung stem cells · Progenitor cells · Regenerative medicine ·

Stem cell therapy

\begin{abstract}
Over the past few years, new insights have been added to the study of stem cells in the adult lung. The exploration of endogenous lung progenitors as well as the study of exogenously delivered stem cell populations holds promise for advancing our understanding of the biology of lung repair mechanisms. Moreover, it opens new possibilities for the use of stem cell therapy for the development of regenerative medicine approaches for the treatment of lung disease. Here, we discuss the main types of lung epithelial progenitor populations; the potential of endothelial progenitors, mesenchymal stem cells and embryonic stem cells for lung therapy, as well as summarize the cellular mechanisms involved.

Copyright $\odot 2013$ S. Karger AG, Basel
\end{abstract}

Previous articles in this series: 1. Bouros D, Laurent G: Regenerative medicine and stem cells: Prometheus revisited. Respiration 2013;85:1-2. 2. Kolios G, Moodley Y: Introduction to stem cells and regenerative medicine. Respiration 2013;85:3-10.

\section{KARGER}

E-Mail karger@karger.com

www.karger.com/res

\section{Introduction}

Lung disease is one of the leading causes of death in the world. Current treatments are focused on improving the quality of life of lung disease patients by reducing inflammation or pharmacologically inhibiting disease-specific pathways [1]. Regenerative medicine treatments that attempt to reverse structural damage to the lungs are scant at best. Focused on harnessing the power of stem cells, regenerative medicine attempts to utilize the body's inherent regenerative capacities to restore function to damaged cells, tissues and organs.

Here, we provide a concise summary of the current knowledge and challenges regarding the main lung progenitor populations (fig. 1), the mechanisms regulating their behavior and their potential to initiate or augment lung repair.

\section{Endogenous Lung Stem and Progenitor Cells}

Rapidly renewing tissues contain rare populations of tissue-specific adult stem cells that have the capacity to proliferate and give rise to transit amplifying cells, which in turn can give rise to differentiated cells. In some tissues, differentiated cells can also be stimulated to proliferate upon homeostatic pressure or injury. These cells, usually (c) 2013 S. Karger AG, Basel

0025-7931/13/0852-0089 \$38.00/0
Maria Mirotsou

GSRBII, Room 4022

210 Research Drive

Durham, NC 27705 (USA)

E-Mail maria.mirotsou@ duke.edu 


\begin{tabular}{|c|c|c|}
\hline Cell type & Markers & Lineages \\
\hline Basal cells & $\begin{array}{l}\text { Trp63+, Krt5+/Krt14+, NGFR+, } \\
\text { Pdpn+ }\end{array}$ & $\begin{array}{l}\text { ciliated } \\
\text { secretory }\end{array}$ \\
\hline AEC2 & Sftpc+ & AEC1 \\
\hline Clara cells & Scgbla1+ & $\begin{array}{l}\text { ciliated } \\
\text { secretory (including goblet) }\end{array}$ \\
\hline Clara variant cells & Scgb1a1+, \pm Upka3/Scgb3a2 & $\begin{array}{l}\text { ciliated } \\
\text { secretory }\end{array}$ \\
\hline Distal lung progenitors & Itga6b4+, Sftpc-, Scgb1a1-, Krt5- & $\begin{array}{l}\text { Scgb1a1+ } \\
\text { Sftpc+ }\end{array}$ \\
\hline Distal airway stem cells & Krt5+ Trp63+ & alveolar pods of epithelial cells \\
\hline Bronchoalveolar stem cells & Scgbla1+, Sftpc+ & $\begin{array}{l}\text { Sftpc+ } \\
\text { Scgbla1+ }\end{array}$ \\
\hline Submucosal gland duct cell & $\mathrm{K} 14+, \mathrm{K} 18+$ & - \\
\hline
\end{tabular}

Fig. 1. Summary of resident stem and progenitor cell types in the lung (table modified from Rock and Königshoff [69]).

termed facultative progenitor cells, (a) show highly infrequent proliferation, but, following injury, they can undergo transition to a continuous proliferation state and (b) possess the ability to transition from a differentiated state to an undifferentiated state and vice versa between normal and injury/repair conditions [2].

Although cells with both stem cell and facultative progenitor cell characteristics have been identified in the lung, their classification has been challenging, and it is still controversial whether true adult lung stem cells exist. Studies in mice have shown that, under normal conditions, these progenitor cells are sufficient to maintain the epithelium [3]. However, evidence for their capacity to regenerate the lung following acute injury is still lacking. Nevertheless, several studies have identified airway epithelial cells that have the ability to enter the cell cycle after injury to the lungs and thus be considered as facultative progenitor cells: basal, Clara-like, Clara, pulmonary neuroendocrine and alveolar type II cells [4]. These cells show high regional specialization of functions [5]. The lung microenvironment, containing a number of different cell types, diverse extracellular matrix proteins and other growth factors, constitutes a 'stem cell niche', which is essential in determining the progenitor cell function and differential potency [5]. As a result, resident lung progenitor cell populations can further be classified by their location in the lung: intralobar airways, tracheobronchial region, bronchoalveolar duct junctions and the alveoli.

\section{Intralobar Airways}

The columnar epithelium lining the distal intralobar airways of the mouse lung is mainly composed of multiciliated and secretory cells lacking basal cells. Early experiments have shown that mature ciliated cells are postmitotic and thus do not contribute to the maintenance of the airway epithelium under steady-state conditions or in response to injury [6]. In contrast, several studies have shown that following injury to the mouse bronchioles, Clara-like cells can both self-renew and give rise to new ciliated cells [6-8]. For instance, it has been shown that a special subset of Clara cells known as variant Clara cells, which are resistant to naphthalene injury, have the potential to self-renew and generate ciliated cells, making them candidate stem cells of the intralobar airway epithelium $[9,10]$. However, it is uncertain whether these cells are actually naphthalene-resistant secretory cells or simply immature secretory cells that lack enzymes for naphthalene metabolism [3]. It is hypothesized that the niche for these variant Clara cells are the neuroepithelial bodies that contain clusters of neuroendocrine cells [11]. However, the precise peptides and growth factors secreted by neuroepithelial bodies that act on adjacent secretory cells are still largely unknown though [10]. In addition, naphthalene-resistant Clara cells have been identified at the bronchoalveolar duct junction $[2,10]$. These cells coexpress Scgb1a1 (secretoglobin 1a1), a marker of Clara cells, and an alveolar type II cell marker, SftpC (surfactant protein C), and proliferate upon lung injury. Based on their in vitro differentiation potential, it has been proposed 
that they are bronchoalveolar stem cells that give rise to both bronchiolar and alveolar cells in vivo [12, 13]. However, further studies using lineage tracing demonstrated that there was no contribution of lineage-tagged Clara cells to alveolar epithelia during either steady-state homeostasis or after hyperoxic injury [12]. Other identified stem cell populations in the intralobar mouse airways include EpCAMhi/CD104+/CD24- cells [14].

\section{Tracheobronchial Region}

The tracheobronchial region is also known as the lung airway and extends from the trachea to the terminal bronchioles. Basal cells being positive for protein markers such as Trp63, cytokeratins 5 and 14, and nerve growth factor receptor (Ngfr) constitute multipotent progenitor cells of the tracheobronchial region [15-17]. Indeed, these cells not only show capacity for self-renewal and clonal expansion, but they are also capable of giving rise to basal, ciliated and secretory lineages, both during steady state and epithelium repair conditions following damage [15-17]. Differences between the various basal cell subpopulations, however, do exist and the differentiation time points, differentiation mechanisms and niches of all these basal cells remain a topic of much study [18, 19]. As an example, it has been shown that asymmetric division of differentiating basal cells to generate multipotent Trp63- Krt8+ luminal early progenitors is a Notchdependent process [20]. It is hypothesized that these early progenitors have limited capacity for proliferation and in response to a second Notch signaling event will generate terminally differentiated ciliated or secretory cells [20]. Indeed, sustained high levels of Notch signals drive differentiation of basal cells into Scgbla1+ and Spdef+ Muc5AC+ secretory cells instead of ciliated cells [20].

In the trachea, the majority of Scgbla1+ Clara cells behave as transit amplifying cells derived from an unknown progenitor [12]. However, it cannot be excluded that there is a small population of long-term self-renewing Clara cells in the trachea as the lineage label is maintained in a small percentage of tracheal Clara cells for up to 1 year [12].

\section{Alveoli}

The alveolar epithelium consists of type I and type II alveolar epithelial cells (AEC1 and AEC2). Cell turnover in the alveolar region of the adult mouse lung is normally 28-35 days [21], which is fairly slow. Pulse-labeling experiments have demonstrated that AEC2 cells actually give rise to AEC1 cells during development and in response to injury [22]. It is hypothesized that damage to

Lung Stem Cells and Progenitor Cells alveolar capillary endothelial cells leads to the release of local cytokines and signaling factors that promote the proliferation and differentiation of type II AECs [23]. It is also possible that death of type I AECs leads to denudation of the alveolar basal lamina, triggering the proliferation and expansion of type II AECs as well as their differentiation to type I cells [23].

Interestingly, recent studies have identified novel populations that hold the potential of distal lung progenitors. Among those, Chapman et al. [24] have reported that a subset of AECs expressing the laminin receptor $\alpha 6 \beta 4$, but little or no prosurfactant $\mathrm{C}$, which holds regenerative capacity. Indeed, these cells showed capacity for both airway and alveolar differentiation in vitro and appeared to proliferate in response to lung bleomycin injury in vivo.

In addition, using a model of $\mathrm{H} 1 \mathrm{~N} 1$ influenza virusinduced airway and alveolar region damage, Kumar et al. [25] have identified a progenitor population of Trp63+ Krt5+ basal cells in the peribronchiolar region. These cells proliferated after injury and were shown to give rise to several epithelial 'pods' in the distal lung. The epithelial pods in turn continue to proliferate and give rise to functional alveoli [25]. The precise origin of the ectopic basal cells is currently unknown. It has been postulated that they arise from rare Trp63+ cells in the smallest bronchioles through reprogramming of resident cells or that they may be dislodged from more proximal regions of the lung $[19,26]$.

\section{Circulating and Exogenously Administered Stem/ Progenitor Cells}

\section{Endothelial Progenitor Cells}

Endothelial progenitor cells (EPCs) were originally described as circulating bone marrow-derived cells that possess the potential to proliferate and differentiate into mature endothelial cells $[27,28]$. EPCs can therefore provide a circulating pool of reservoir cells that could potentially integrate into the site of lung injury and replace damaged endothelium. In addition, isolation and exogenous manipulation of EPCs can constitute a cell source for cell therapeutic approaches for lung injury.

However, no clear consensus regarding the identity of EPCs exist and the term is used to describe a number of cell types with putative roles in vascular homeostasis and disease $[29,30]$. Nevertheless, there is some agreement that two main types of EPCs can be isolated from human peripheral blood and cultured in vitro: early and late outgrowth EPCs. Early EPCs are CD34+ CD31+ CD14+, 
have a spindle-shaped morphology, grow early in vitro, cannot form tubes in a Matrigel tube-forming assay, and secrete high levels of growth factor and cytokines. Late outgrowth EPCs appear after 2 weeks of culture, are CD31+ CD144+ CD146+ CD105+ CD45- CD14CD115-, have a cobblestone-like shape and possess the unique ability to spontaneously form human blood vessels in certain environments. In the context of the lungs, it is postulated that early EPCs can act as paracrine cells while late EPCs can function to restore vasculature structures [4]. Indeed, when infused together, the two seem to play a synergistic role in restoring vascular structure and function [31]. Interestingly, resident microvascular EPCs have been identified in the pulmonary microvascular endothelium of mouse, rat and human lung [32]. These cells seem to possess rapid vasculogenic capacity compared to EPCs derived from other sources [32].

In vivo, circulating EPCs can be recruited from the periphery and potentially integrate in sites of injury and promote repair by enhancing neovascularization. This can happen by either their direct differentiation to more mature vascular cells or by the release of paracrine factors that promote cell growth and angiogenesis [33]. Disease state, age and lifestyle choices, all have been shown to reduce EPC counts and their potential reparative capacity [reviewed in ref. 34 and references therein]. Recent evidence suggests that hypoxia might play an important role in EPC mobilization, growth and differentiation, however, the precise mechanisms are unclear. Still, the numbers of circulating EPCs do seem to correlate with lung disease states. For example, increased circulating EPC numbers generally correlate with better survival and less residual lung [35-37]. However, there are cases such as non-small cell lung cancer where increased numbers of circulating EPCs correlate with worse survival $[38,39]$.

\section{Mesenchymal Stem Cells}

Perhaps the most heavily researched of nonresident stem cells of the lung are bone marrow-derived mesenchymal stem cells or mesenchymal stromal cells (MSCs). It is important to note that MSCs represent a 'heterogeneous' population expressing different levels of a panel of cell surface markers which, although not specific, in combination are associated with defining MSCs. MSCs are further defined by cell attachment, self-renewal, clonogenicity and the ability to differentiate towards multiple lineages [40, 41]. The minimal criteria for defining human MSCs, as recommended by the Mesenchymal and Tissue Stem Cell Committee of the International Society for Cellular Therapy as of 2006, are as follows: (a) plastic adher-

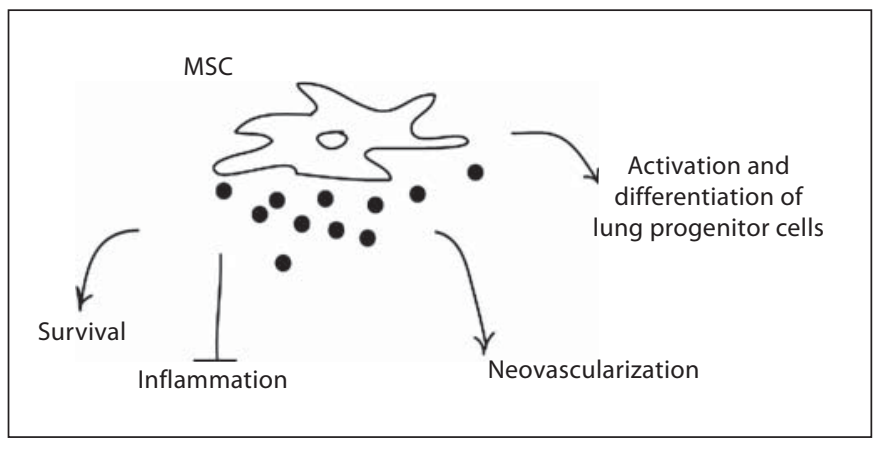

Fig. 2. Overview of MSC paracrine effects in the lung.

ence in standard tissue culture conditions; (b) expression of CD73, CD90 and CD105; (c) no expression for CD11b, CD14, CD34, CD45, CD79a/CD19 and HLA-DR-, and (d) differentiation in vitro to osteoblasts, adipocytes and chondroblasts [42]. Interestingly, MSC-like cells have been isolated from adult mouse [43-45] and human lung tissue [46-48]. However, the physiologic importance of these cell populations is still under investigation.

Transplantation of MSCs offers many advantages for regenerative therapy as MSCs are immunologically well tolerated, which allows for administration of allogenic MSCs without significant host responses [49]. Furthermore, they can be expanded ex vivo and easily manipulated genetically to enhance their survival and engraftment as well as the delivery-desired molecules [50]. While a major effort in MSC research has been focused on their regenerative capacity, several studies have reported that MSCs can play a role in tissue repair by the secretion of paracrine factors that activate cytoprotection, cell growth, neovascularization and immunomodulation $[40,51,52]$.

In regard to lung therapy, MSCs can be induced in vitro to express markers of either airway or AECs [53]. However, this is a rare event [54] and emphasis has been shifted to their paracrine properties (fig. 2). For example, soluble mediators released by MSCs such as interleukin (IL)-1 receptor antagonist, IL-10, keratinocyte growth factor, hepatocyte growth factor, angiopoietin 1 and transforming growth factor- $\beta$ appear to play a significant role in the repair of acute and fibrotic injuries [55-57; also summarized in 4], however the actual mechanisms by which they do this are not yet fully understood. Of note, several studies support a role of MSC in lung inflammation and injury by modulation of the immune system. Indeed, MSCs secrete anti-inflammatory agents such IL-1 receptor antagonist, IL-6, IL-10 and prostaglandin $\mathrm{E}_{2}$ [58] while they can sup- 
press in parallel proinflammatory cytokine expression (i.e. tumor necrosis factor- $\alpha$-stimulated gene/protein 6) [54]. In addition, MSCs can also secrete anti-microbial peptides such as LL-37 [59] and tumor necrosis factor- $\alpha$-induced protein $6[60,61]$. Indeed, in vivo delivery of mesenchymal stem cells increased bacterial clearance and enhanced host cell phagocytosis in septic mice $[61,62]$.

\section{Embryonic Stem Cells/Induced Pluripotent Stem Cells}

Embryonic stem cells (ESCs) are derived from the inner cell mass of the blastocyst. They are undifferentiated, pluripotent cells. In a well-defined culture, they can be maintained indefinitely in this state, or they can be directed towards a specific cell fate [63]. Recently, it was shown that stem cells could be generated from somatic cells by cellular reprogramming [64]. These induced pluripotent cells (iPS), they do appear very similar morphologically to ESCs and do possess the same ability to differentiate into cell types from all three germ layers [64].

This raises the possibility that for generating patientspecific iPS stem cells or generating gene-corrected iPS for individuals with genetic diseases such as cystic fibrosis or $\alpha_{1}$-antitrypsin deficiency [65].

Several studies over the past few years have shown that both mouse and human ESCs can be induced in culture to generate cells with phenotypic characteristics of type II alveolar epithelial cells. These include expression of surfactant proteins and lamellar bodies, and the formation of pseudoglandular structures [66]. Moreover, it has been shown that intratracheal administration of the AEC2 cells derived from human ESCs (hESCs) in a bleomycin-induced lung injury mouse model resulted in the engraftment and hESC-derived SPS-expressing cells. Importantly, mice receiving AEC2 cells derived from hESCs showed significant reduction in lung injury compared to controls [67]. Using a similar model of lung injury, Soh et al. [68] have shown recently that transplantation of hESCs and iPS-derived CD166+ lung epithelial progenitor cells resulted in enhanced survivability of mice and improved lung pulmonary function. Despite the progress, genera- tion of lung epithelia from ES or iPS and their therapeutic application remain challenging. These challenges include the complexity and lack of knowledge of the lung epithelial cell phenotype, the need for improved protocols and the tumorigenicity of the implanted tissue due to the presence of undifferentiated pluripotent stem cells.

\section{Challenges and Future Directions}

Despite the progress, uncovering the mechanisms by which progenitor/stem cell populations in the lung maintain homeostasis has been proven to be very challenging. One of the most significant challenges is the identification of appropriate/specific markers for endogenous lung stem/progenitor cell populations in both rodents and humans. Progress has additionally been slowed by the complex 3D structure of the lung, which has made it difficult to perform live monitoring of progenitor cells or of any microcellular interactions during development and repair. The development of better genetic tools (cell lineage tracing methods) as well advancements in the area of tissue engineering (to allow 3D studies ex vivo) can significantly contribute to the further development of the field. In addition, significant gaps remain in our knowledge regarding the development of lung cell therapy protocols. Indeed, optimal methods for cell administration, dosage regimens and efficacy still need to be addressed. Future studies hold promise for providing new insights into the biology of lung stem cells as well for the translation of preclinical studies to new therapeutic modalities for lung disease therapy.

\section{Acknowledgments}

This work was supported by Grants from the American Heart Association (10SDG4280011) and National Heart, Lung, and Blood Institute (HL081744) and the Edna Mandel Foundation. We apologize to our colleagues whose work has not been cited due to space constraints.
References

Lung Stem Cells and Progenitor Cells
Respiration 2013;85:89-95 
5 Fuchs E, Tumbar T, Guasch G: Socializing with the neighbors: stem cells and their niche. Cell 2004;116:769-778.

-6 Rawlins EL, Ostrowski LE, Randell SH, Hogan BL: Lung development and repair: contribution of the ciliated lineage. Proc Natl Acad Sci USA 2007;104:410-417.

-7 Evans MJ, Shami SG, Cabral-Anderson LJ, Dekker NP: Role of nonciliated cells in renewal of the bronchial epithelium of rats exposed to $\mathrm{NO}_{2}$. Am J Pathol 1986;123:126133.

8 Reynolds SD, Giangreco A, Power JH, Stripp BR: Neuroepithelial bodies of pulmonary airways serve as a reservoir of progenitor cells capable of epithelial regeneration. Am J Pathol 2000;156:269-278.

-9 Hong KU, Reynolds SD, Giangreco A, Hurley CM, Stripp BR: Clara cell secretory proteinexpressing cells of the airway neuroepithelial body microenvironment include a label-retaining subset and are critical for epithelial renewal after progenitor cell depletion. Am J Respir Cell Mol Biol 2001;24:671-681.

10 Giangreco A, Reynolds SD, Stripp BR: Terminal bronchioles harbor a unique airway stem cell population that localizes to the bronchoalveolar duct junction. Am J Pathol 2002; 161:173-182.

11 Linnoila RI: Functional facets of the pulmonary neuroendocrine system. Lab Invest 2006; 86:425-444.

- 12 Rawlins EL, Okubo T, Xue Y, Brass DM, Auten RL, Hasegawa $\mathrm{H}$, et al: The role of Scgbla1+ Clara cells in the long-term maintenance and repair of lung airway, but not alveolar, epithelium. Cell Stem Cell 2009;4: 525-534.

$\checkmark 13$ Kim CF, Jackson EL, Woolfenden AE, Lawrence S, Babar I, Vogel S, et al: Identification of bronchioalveolar stem cells in normal lung and lung cancer. Cell 2005;121:823-835.

14 McQualter JL, Yuen K, Williams B, Bertoncello I: Evidence of an epithelial stem/progenitor cell hierarchy in the adult mouse lung. Proc Natl Acad Sci USA 2010;107:1414-1419.

- 15 Rock JR, Onaitis MW, Rawlins EL, Lu Y, Clark CP, Xue Y, et al: Basal cells as stem cells of the mouse trachea and human airway epithelium. Proc Natl Acad Sci USA 2009;106: 12771-12775.

16 Hong KU, Reynolds SD, Watkins S, Fuchs E, Stripp BR: In vivo differentiation potential of tracheal basal cells: evidence for multipotent and unipotent subpopulations. Am J Physiol Lung Cell Mol Physiol 2004;286:L643-L649.

-17 Cole BB, Smith RW, Jenkins KM, Graham BB, Reynolds PR, Reynolds SD: Tracheal basal cells: a facultative progenitor cell pool. Am J Pathol 2010;177:362-376.

- 18 Rock JR, Randell SH, Hogan BL: Airway basal stem cells: a perspective on their roles in epithelial homeostasis and remodeling. Dis Model Mech 2010;3:545-556.

19 Rock J, Königshoff M: Endogenous lung regeneration: potential and limitations. Am J Respir Crit Care Med 2012;186:1213-1219.
20 Rock JR, Gao X, Xue Y, Randell SH, Kong YY, Hogan BL: Notch-dependent differentiation of adult airway basal stem cells. Cell Stem Cell 2011;8:639-648.

21 Kauffman SL: Cell proliferation in the mammalian lung. Int Rev Exp Pathol 1980;22:131191.

22 Evans MJ, Cabral LJ, Stephens RJ, Freeman G: Transformation of alveolar type 2 cells to type 1 cells following exposure to $\mathrm{NO}_{2}$. Exp $\mathrm{Mol}$ Pathol 1975;22:142-150.

23 Wansleeben C, Barkauskas CE, Rock JR, Hogan BLM: Stem cells of the adult lung: their development and role in homeostasis, regeneration, and disease. WIREs Dev Biol 2013;2:131-148.

24 Chapman HA, Li X, Alexander JP, Brumwell A, Lorizio W, Tan K, et al: Integrin $\alpha_{6} \beta_{4}$ identifies an adult distal lung epithelial population with regenerative potential in mice. J Clin Invest 2011;121:2855-2862.

25 Kumar PA, Hu Y, Yamamoto Y, Hoe NB, Wei TS, Mu D, et al: Distal airway stem cells yield alveoli in vitro and during lung regeneration following H1N1 influenza infection. Cell 2011;147:525-538.

26 Kotton DN: Next-generation regeneration: the hope and hype of lung stem cell research. Am J Respir Crit Care Med 2012;185:12551260.

27 Asahara T, Murohara T, Sullivan A, Silver M, van der Zee R, Li T, et al: Isolation of putative progenitor endothelial cells for angiogenesis. Science 1997;275:964-967.

28 Hristov M, Erl W, Weber PC: Endothelial progenitor cells: mobilization, differentiation, and homing. Arterioscler Thromb Vasc Biol 2003;23:1185-1189.

29 Yoder MC, Mead LE, Prater D, Krier TR, Mroueh KN, Li F, et al: Redefining endothelial progenitor cells via clonal analysis and hematopoietic stem/progenitor cell principals. Blood 2007;109:1801-1809.

30 Hirschi KK, Ingram DA, Yoder MC: Assessing identity, phenotype, and fate of endothelial progenitor cells. Arterioscler Thromb Vasc Biol 2008;28:1584-1595.

- 31 Yoon CH, Hur J, Park KW, Kim JH, Lee CS, Oh IY, et al: Synergistic neovascularization by mixed transplantation of early endothelial progenitor cells and late outgrowth endothelial cells: the role of angiogenic cytokines and matrix metalloproteinases. Circulation 2005; 112:1618-1627.

32 Yoder MC: Progenitor cells in the pulmonary circulation. Proc Am Thorac Soc 2011;8:466470.

33 Takahashi T, Suzuki S, Kubo H, Yamaya M, Kurosawa S, Kato M: Impaired endothelial progenitor cell mobilization and colonyforming capacity in chronic obstructive pulmonary disease. Respirology 2011;16:680687.
34 Mao M, Xu X, Zhang Y, Zhang B, Fu Z-H: Endothelial progenitor cells: the promise of cell-based therapies for acute lung injury. Inflamm Res 2012, DOI: 10.1007/s00011-0120570-3.

-35 Burnham EL, Taylor WR, Quyyumi AA, Rojas M, Brigham KL, Moss M: Increased circulating endothelial progenitor cells are associated with survival in acute lung injury. Am J Respir Crit Care Med 2005;172:854-860.

- 36 Yamada M, Kubo H, Ishizawa K, Kobayashi S, Shinkawa M, Sasaki H: Increased circulating endothelial progenitor cells in patients with bacterial pneumonia: evidence that bone marrow derived cells contribute to lung repair. Thorax 2005;60:410-413.

-37 Toshner M, Voswinckel R, Southwood M, AlLamki R, Howard LSG, Marchesan D, et al: Evidence of dysfunction of endothelial progenitors in pulmonary arterial hypertension. Am J Respir Crit Care Med 2009;180:780787.

38 Bogos K, Renyi-Vamos F, Dobos J, Kenessey I, Tovari J, Timar J, et al: High VEGFR-3-positive circulating lymphatic/vascular endothelial progenitor cell level is associated with poor prognosis in human small cell lung cancer. Clin Cancer Res 2009;15:1741-1746.

-39 Nowak K, Rafat N, Belle S, Weiss C, Hanusch $\mathrm{C}$, Hohenberger $\mathrm{P}$, et al: Circulating endothelial progenitor cells are increased in human lung cancer and correlate with stage of disease. Eur J Cardiothorac Surg 2010;37:758-763.

40 Keating A: Mesenchymal stromal cells: new directions. Stem Cell 2012;10:709-716.

41 Nombela-Arrieta C, Ritz J, Silberstein LE: The elusive nature and function of mesenchymal stem cells. Nat Rev Mol Cell Biol 2011;12: 126-131.

42 Dominici M, Le Blanc K, Mueller I, SlaperCortenbach I, Marini F, Krause D, et al: Minimal criteria for defining multipotent mesenchymal stromal cells. The International Society for Cellular Therapy position statement. Cytotherapy 2006;8:315-317.

43 Gadepalli VS, Vaughan C, Rao RR: Isolation and characterization of murine multipotent lung stem cells. Methods Mol Biol 2013;962: 183-191.

44 Summer R, Fitzsimmons K, Dwyer D: Isolation of an adult mouse lung mesenchymal progenitor cell population. Am J Respir Cell Mol Biol 2007:37:152-159.

-45 Kajstura J, Rota M, Hall SR, Hosoda T, D'Amario D, Sanada F, et al: Evidence for human lung stem cells. N Engl J Med 2011;364: 1795-1806.

46 Lama VN, Smith L, Badri L, Flint A: Evidence for tissue-resident mesenchymal stem cells in human adult lung from studies of transplanted allografts. J Clin Invest 2007117:989-996.

47 Bozyk PD, Popova AP, Bentley JK, Goldsmith AM, Linn MJ, Weiss DJ, et al: Mesenchymal stromal cells from neonatal tracheal aspirates demonstrate a pattern of lung-specific gene expression. Stem Cells Dev 2011;20:19952007. 
-48 Covas DT, Panepucci RA, Fontes AM, Silva WA: Multipotent mesenchymal stromal cells obtained from diverse human tissues share functional properties and gene-expression profile with CD146+ perivascular cells and fibroblasts. Exp Hematol 2008;36:642-654.

49 DelaRosa O, Lombardo E: Modulation of adult mesenchymal stem cells activity by tolllike receptors: implications on therapeutic potential. Mediators Inflamm 2010, DOI: 10.1155/2010/865601.

50 Hodgkinson CP, Gomez JA, Mirotsou M, Dzau VJ: Genetic engineering of mesenchymal stem cells and its application in human disease therapy. Hum Gene Ther 2010;21: 1513-1526.

-51 Mirotsou M, Jayawardena TM, Schmeckpeper J, Gnecchi M, Dzau VJ: Paracrine mechanisms of stem cell reparative and regenerative actions in the heart. J Mol Cell Cardiol 2011; 50:280-289.

-52 Lee JW, Fang X, Krasnodembskaya A, Howard JP: Concise review: mesenchymal stem cells for acute lung injury: role of paracrine soluble factors. Stem Cells 2011;29:913-919.

53 Ricciardi M, Malpeli G, Bifari F, Bassi G, Pacelli L, Nwabo Kamdje AH, et al: Comparison of epithelial differentiation and immune regulatory properties of mesenchymal stromal cells derived from human lung and bone marrow. PLoS One 2012;7:e35639.

54 Prockop DJ: Repair of tissues by adult stem/ progenitor cells (MSCs): controversies, myths, and changing paradigms. Mol Ther 2009; 17:939-946.

55 Akram KM, Samad S, Spiteri M, Forsyth NR: Mesenchymal stem cell therapy and lung diseases. Adv Biochem Eng Biotechnol 2012, Epub ahead of print.
56 Mei SH, McCarter SD, Deng Y, Parker CH, Liles WC, Stewart DJ: Prevention of LPS-induced acute lung injury in mice by mesenchymal stem cells overexpressing angiopoietin 1 . PLoS Med 2007;4:e269.

57 Aslam M, Baveja R, Liang OD, FernandezGonzalez A, Lee C, Mitsialis SA, et al: Bone marrow stromal cells attenuate lung injury in a murine model of neonatal chronic lung dis ease. Am J Respir Crit Care Med 2009;180: 1122-1130.

58 Németh K, Leelahavanichkul A, Yuen PST, Mayer B, Parmelee A, Doi K, et al: Bone marrow stromal cells attenuate sepsis via prostaglandin $\mathrm{E}(2)$-dependent reprogramming of host macrophages to increase their interleukin-10 production. Nat Med 2009;15:42-49.

59 Krasnodembskaya A, Song Y, Fang X, Gupta N, Serikov V, Lee JW, et al: Antibacterial effect of human mesenchymal stem cells is me diated in part from secretion of the antimicrobial peptide LL-37. Stem Cells 2010;28:22292238.

60 Danchuk S, Ylostalo JH, Hossain F, Sorge R, Ramsey A, Bonvillain RW, et al: Human multipotent stromal cells attenuate lipopolysaccharide-induced acute lung injury in mice via secretion of tumor necrosis factor- $\alpha$-induced protein 6. Stem Cell Res Ther 2011;2:27.

61 Hayes M, Curley G, Laffey JG: Mesenchyma stem cells - a promising therapy for acute respiratory distress syndrome. F1000 Med Rep 2012;4:2.

62 Mei SHJ, Haitsma JJ, Santos Dos CC, Deng Y, Lai PFH, Slutsky AS, et al: Mesenchymal stem cells reduce inflammation while enhancing bacterial clearance and improving survival in sepsis. Am J Respir Crit Care Med 2010;182: 1047-1057.
63 Odorico JS, Kaufman DS, Thomson JA: Multilineage differentiation from human embryonic stem cell lines. Stem Cells 2001;19:193204.

64 Takahashi K, Yamanaka S: Induction of pluripotent stem cells from mouse embryonic and adult fibroblast cultures by defined factors. Cell 2006;126:663-676.

65 Somers A, Jean JC, Sommer CA, Omari A, Ford CC, Mills JA, et al: Generation of transgene-free lung disease-specific human induced pluripotent stem cells using a single excisable lentiviral stem cell cassette. Stem Cells 2010;28:1728-1740.

66 Wetsel RA, Wang D, Calame DG: Therapeutic potential of lung epithelial progenitor cells derived from embryonic and induced pluripotent stem cells. Annu Rev Med 2011;62:95105.

67 Wang D, Morales JE, Calame DG, Alcorn JL, Wetsel RA: Transplantation of human embryonic stem cell-derived alveolar epithelial type II cells abrogates acute lung injury in mice. Mol Ther 2010;18:625-634.

68 Soh BS, Zheng D, Li Yeo JS, Yang HH, Ng SY, Wong LH, et al: CD166(pos)subpopulation from differentiated human ES and iPS cells support repair of acute lung injury. Mol Ther 2012;20:2335-2346.

69 Rock J, Königshoff M: Endogenous lung regeneration: potential and limitations. Am J Respir Crit Care Med 2012;186:1213-1239. 